\title{
DA TRIPARTIÇÃO DE PODERES AO ESTADO DE COISAS INCONSTITUCIONAL E O "COMPROMISSO SIGNIFICATIVO": A contemporânea atuação do Poder Judiciário na solução de conflitos que envolvem direitos sociais fundamentais
}

\author{
THE POWERS OF THE UNCONSTITUTIONAL TRIPARTISM \\ THINGS STATE AND “COMMITMENT SIGNIFICANT" \\ The contemporary role of the judiciary in resolving conflicts \\ involving fundamental social rights
}

\author{
Renato BERNARDI ${ }^{1}$ \\ Ana Paula MEDA ${ }^{2}$ \\ Artigo recebido em: 24/05/2016 \\ Artigo aprovado em: 27/08/2016
}

RESUMO: O trabalho tem a pretensão de estudar e anunciar a evolução histórica da atuação do Poder Judiciário brasileiro no controle jurisdicional das políticas públicas. Partindo do papel de "legislador negativo" para uma postura mais

\footnotetext{
${ }^{1}$ Bacharel em Direito pela Instituição Toledo de Ensino - ITE, Mestre em Direito Constitucional pela Instituição Toledo de Ensino - ITE e Doutor em Direito do Estado (subárea Direito Tributário) pela Pontifícia Universidade Católica de São Paulo - PUC-SP. Professor efetivo dos cursos de Pós-Graduação stricto sensu - Mestrado e Doutorado - e do curso de Graduação da Faculdade de Direito do Centro de Ciências Sociais Aplicadas da Universidade Estadual do Norte do Paraná - UENP, Campus de Jacarezinho. Coordenador do PROJURIS Estudos Jurídicos Ltda. Professor dos cursos de pós-graduação lato sensu - Especialização - do PROJURIS/FIO. Coordenador do TCC no CCSA-UENP, campus de Jacarezinho, Coordenador de Extensão no CCSA-UENP, campus de Jacarezinho, Coordenador da Comissão de Extensão do campus da UENP de Jacarezinho, Membro do Comitê de Iniciação à Extensão da UENP, Membro da Comissão de Coordenação do Programa de Mestrado em Ciência Jurídica no CCSA-UENP, campus de Jacarezinho, Membro do Conselho Curador da Escola Superior da Procuradoria Geral do Estado de São Paulo. Procurador do Estado de São Paulo desde 1994. E-mail: bernardi@uenp.edu.br

${ }^{2}$ Graduada pela UENP/Jacarezinho (2011-2015). É mestranda em Ciência Jurídica pela mesma instituição. Atua como advogada no Núcleo de Estudos e Defesa dos Direitos da Infância e Juventude (NEDDIJ) do Centro de Ciências Sociais Aplicadas da UENP. Integrante dos Grupos de Pesquisa Democracia e Direitos Fundamentais; A Interferência do Estado na Vida da Pessoa Humana; e A Eficácia dos Direitos Fundamentais no Brasil. Foi bolsista de Iniciação Científica (2013-2015) PIBIC/UENP - Fundação Araucária de Apoio ao Desenvolvimento Científico e Tecnológico (FAADCT/PR). E-mail: napaula.meda@yahoo.com.br
} 
ativa e assertiva, Poder Judiciário e, em especial, o STF passou a ter maior protagonismo em sua relação com os demais Poderes, o que se convencionou chamar de "ativismo judicial". Esse "ativismo judicial" atingiu, aparentemente, seu paroxismo, com a recente decisão do STF no julgamento da Arguição de Descumprimento de Preceito Fundamental (ADPF) n $n^{\circ} 347$, oportunidade em que foi adotada a doutrinas colombiana do "estado de coisas inconstitucional" como fundamento para a tomada de medidas administrativas pelo Poder Executivo. Sempre com a preocupação de respeito ao princípio da tripartição de Poderes, o estudo prossegue sugerindo a maior conveniência de se adotar o instituto do "compromisso significativo", construção jurisprudencial da Corte Constitucional da África do Sul, que prioriza a solução compartilhada entre os Poderes e a sociedade para assegurar a concretização de direitos.

PALAVRAS-CHAVE: Ativismo judicial, políticas públicas, estado de coisas inconstitucional, compromisso significativo.

ABSTRACT: The paper purports to study and announce the historical evolution of the Brazilian Judiciary acting in judicial control of public policies. Starting from the role of "negative legislator" to a more active and assertive stance, Judiciary and in particular the Supreme Court now has major role in its relationship with the other branches, the so-called "judicial activism." This "judicial activism" reached apparently its paroxysm, the recent decision of the Supreme Court in the trial of accusation of breach of fundamental precept (ADPF) 347, at which it was adopted the Colombian doctrines of "state of affairs unconstitutional" the foundation for taking administrative measures by the Executive. Always with the concern of respect for the principle of tripartism powers, the study goes on to suggest the convenience of adopting the institute's "significant commitment" jurisprudential construction of the Constitutional Court of South Africa, which prioritizes the shared solution between the Powers and society to ensure the realization of rights.

KEYWORDS: judicial activism, public policy, unconstitutional state of things, significant commitment. 


\section{Introdução}

O Poder Judiciário vem ganhando contornos de "pedra de toque" na manutenção e na eficácia dos denominados Direitos Fundamentais. Tal categoria de direitos, ante a inexistência ou insuficiência de políticas públicas garantidoras, passou a se tornar de difícil acesso à parte da sociedade que mais dele carece. O vácuo Legislativo garantidor da falta de eficácia dos direitos fundamentais, aliado à constante omissão do Poder Executivo, transferiu ao Poder Judiciário o condão de fazer valer os ditames constitucionais fundamentais, em especial aqueles que preveem Direitos de cunho social.

Era pacífico o entendimento de que à Corte Suprema somente era autorizada a atuação como "legislador negativo", no sentido de suspender - na hipótese de julgamento de liminares -, ou eliminar - no caso de julgamento de mérito -, os dispositivos considerados inconstitucionais.

Não era lícito aguardar do STF uma atuação como "legislador positivo", propondo soluções normativas para as hipóteses em que declarava a inconstitucionalidade das normas, por ação ou omissão.

Posteriormente, essa postura foi alterada, tendo o STF passado a atuar de forma mais ativa na construção de alternativas normativas nas hipóteses de declaração de inconstitucionalidade das normas.

Admitiu-se, excepcionalmente, com o passar do tempo, o controle jurisdicional das políticas públicas, quando violadas diretamente as normas expressas, constitucionais e legais, que as parametrizavam.

Nessa perspectiva, a atuação dos Poderes Executivo e Legislativo na formulação das políticas devia obedecer a limites. O limite principal era a preservação do mínimo intangível assegurador da dignidade do ser humano que não podia ser sonegado pela ação estatal (mínimo existencial).

Até que, no Recurso Extraordinário (RE) n ${ }^{\circ}$ 592.581e da ADPF nº 347, no que concerne à evolução da atuação do STF no controle jurisdicional das políticas públicas, no sentido de se reconhecer o "estado de coisas inconstitucional" no funcionamento do sistema prisional brasileiro e esse reconhecimento ser considerado o lastro para uma ação jurisdicional mais efetiva.

O reconhecimento do "estado de coisas inconstitucional" foi decisivo para que o STF determinasse a adoção de medidas administrativas e a alocação de recursos orçamentários para o equacionamento da situação do sistema carcerário nacional, numa guinada jurisprudencial de grande impacto que está 
a suscitar a preocupação de parlamentares, juristas e agentes públicos sobre a necessidade de essa nova linha jurisprudencial ser balizada, com o claro estabelecimento de limites normativos, sob pena de as competências específicas dos demais Poderes - Executivo e Legislativo - serem usurpadas pelo órgão de cúpula do Poder Judiciário nacional.

Cuida-se de saber se a maior flexibilidade na formulação de políticas públicas, na formatação do desenho organizacional do Poder Executivo e na alocação das verbas orçamentárias admitida, excepcionalmente, para o Poder Judiciário, aplica-se, também, à atuação do Poder Legislativo.

Alhures, o trabalho sugere a maior conveniência de se adotar o instituto do "compromisso significativo", construção jurisprudencial da Corte Constitucional da África do Sul, que prioriza a solução compartilhada entre os Poderes e a sociedade para assegurar a concretização de direitos fundamentais como alternativa ao que decidido no julgamento do RE no 592.581 e da ADPF no 347 e, alfim, refere, nesse sentido, a apresentação do Projeto de Lei do Senado (PLS) $n^{\circ}$ 736, de 2015, que intenciona positivar o "compromisso significativo" no sistema de controle concentrado e difuso da constitucionalidade das normas no Brasil.

\section{A tripartição de poderes}

Desde outrora a concentração de poder em uma única figura mostrouse uma ameaça para vida humana. O monarca absolutista, por exemplo, concentrava todo poder em sua pessoa, o que de fato tornava-o imperioso diante de qualquer conjuntura que exercesse sua influência, ou seja, não havia limites para o poder e seu exercício, tratava-se de uma força política interminável.

Ocorre que a mantença de tal sistemática era também a conservação do caos, no sentido da abertura para arbitrariedade do monarca que transformava o poder advindo do povo contra o próprio povo, uma vez que as pessoas ficavam à míngua de direitos e os privilégios eram aplicados aleatoriamente, sem qualquer critério de igualdade, era o realce do ter sobre o ser.

Todavia, o Estado não mais se sustentava. A população em condições precárias clamava por justiça e, então, em 1789, a Revolução Francesa marcou a passagem da centralização do poder monárquico para a descentralização do poderio com o fim das regalias destinadas ao clero e à nobreza, passava-se, desse modo, ao que se chamou tripartição dos poderes.

A origem da ideia da repartição dos poderes, na verdade, adentra lon- 
ga data, na qual, Edinilson Donisete Machado ao consagrar os ensinamentos de Bobbio observa que Aristóteles já operava uma divisão entre "assembleia geral, o corpo de magistrados e o corpo judiciário" e que referida formação percebeu no século XVIII coerência com a lógica de Locke, mas tão somente foi sistematizada na transição do século XVIII para o XIX com Montesquieu (2011, p. 78).

Para Peixinho, o princípio da separação dos poderes como teoria política foi inaugurada por John Locke ao estabelecer três poderes imprescindíveis às sociedades, sendo esses os poderes Legislativo, Executivo e Federativo. Nesta esteia Locke vislumbrou que o Legislativo deveria elaborar as leis, a existir um poder Executivo separado do Legislativo, bem como o Federativo ligado às negociações externas e à guerra (2008, p. 15).

Igualmente pode-se apontar que corroborou para o anseio da tripartição de funções o pensamento de Jean-Jacques Rousseau, pois segundo Alves (2009, p. 95) o objetivo de Rousseau de acordo com sua doutrina política de precisar cada função do poder "é proteger os cidadãos de posturas arbitrárias individuais ou de grupos dentro da ordem política, que possam vir a violar a liberdade e a igualdade entre os cidadãos [...] assegura a atuação do soberano e do governo somente pela lei".

Continuamente, no intuito de limitar o poder e assegurar a liberdade política, Montesquieu estruturou a divisão das funções e construiu uma aspiração fundamental de harmonia entre os órgãos:

A liberdade política vista na Constituição não seria meramente um princípio de organização, mas um direito à participação. Montesquieu, inspirado na teoria esposada por John Locke, entende que os Poderes Legislativo, Executivo e Judicial devem ser atribuídos a pessoas diferentes, sem, contudo, pontuar rigorosa separação entre as funções. Em Montesquieu há verdadeira harmonia que enseja a atribuição conjunta e indivisível de três órgãos, quer dizer, a co-soberania de três órgãos políticos (PEIXINHO, 2008, p. 16).

Em sua obra "O espírito das leis", Montesquieu descreve capítulos sobre o poder legislativo, executivo e também a respeito do poder de julgar. Entre os escritos o autor reconhece que mencionada divisão visa garantir a liberdade política ao que ele denominou "uma certa distribuição dos três poderes" (2000, p. 197). Em interpretação à citada referência nota-se que: 
Quando, na mesma pessoa ou no mesmo corpo de magistratura, o poder legislativo está reunido ao poder executivo, não existe liberdade; porque se pode temer que o mesmo monarca ou o mesmo senado crie leis tirânicas para executá-las tiranicamente. Tampouco existe liberdade se o poder de julgar não for separado do poder legislativo e do executivo. Se estivesse unido ao poder legislativo, o poder sobre a vida e a liberdade dos cidadãos seria arbitrário, pois o juiz seria legislador. Se estivesse unido ao poder executivo, o juiz poderia ter a força de um opressor. [...] A liberdade não pode ser assegurada em um lugar onde apenas um interesse é garantido. Esses poderes na visão de Montesquieu deveriam ser exercidos por pessoas diferentes, impedindo assim que apenas um interesse prepondere (DOURADO; AUGUSTO; ROSA, 2011, 2639-2640).

Destarte afere-se que a liberdade política e dos cidadãos é drasticamente afetada caso os poderes sejam cumulados em uma só pessoa, tendo em conta que ao comportarem competências distintas não devem ser centralizadas em razão de uma gerência articulada da própria arbitrariedade.

Ressalta-se, nesse sentido, que "não se trata de divisão do poder, mas sim de suas funções, com o objetivo de melhor realizar o fim do Estado, por intermédio de seus órgãos ou de suas instituições" (MACHADO, 2011, p. 79), com isso, depreende-se que o poder é uno e o que é passível de repartição são suas funções para que não coadunem em única vertente, a fim de culminar na concentração de atribuições.

Entretanto, Machado verifica que Jellinek não pactuava da mesma ideia acerca da tripartição, criticando a teoria desenvolvida por Montesquieu justamente por entender que o poder do Estado, enquanto soberano, não poderia ser divisível, no entanto, não se divide o poder do Estado, mas sim suas funções (2011, p. 80), por isso a necessidade de acrescentar referido esclarecimento.

Adiante, tem-se que a corrente tripartite de Montesquieu foi aplicada na obra "O Federalista" com autoria de Hamilton, Madison e Jay "de uma forma revigorada para a sua época e, por que não dizer, até os nossos dias, apresentando não uma divisão estanque de funções, mas pela primeira vez se fala em equilíbrio entre os poderes" (MACHADO, 2011, p. 81).

Dessa forma, para que o equilíbrio entre os poderes se sustente é preciso que mecanismos sejam utilizados com o fito de propiciar harmonia, de maneira que uma função não se sobreponha à outra, ou seja, que não haja a usurpação de funções, pois que já estaria ocorrendo um desequilíbrio se assim fosse. 
Com isso, o retorno ao recorte histórico da Revolução Francesa, anteriormente dito neste trabalho, trouxe para as esferas formais e materiais a teoria da separação das funções como mandamento constitucional na Declaração dos Direitos do Homem e do Cidadão de 1789, por se entender como meio imprescindível para a garantia dos direitos dos indivíduos, sendo que passou a partir disso a compor grande parte das Constituições dos Estados de Direito.

Em paralelo, a Constituição brasileira de 1988 dispôs sobre o princípio da divisão das funções na norma inserta no artigo $2^{\circ 3}$, bem como na norma expressa pelo artigo $60, \S 4^{\circ}$, $\mathrm{III}^{4}$, a evidenciar a importância desse princípio como condição para manutenção e procedência de um Estado que respeita os direitos e garantias das pessoas.

Pode-se dizer que além da divisão clássica de funções outro mecanismo de controle fora inserido na ótica limitadora do poder do Estado, é o que se nomeia sistema de checks and balances ou freios e contrapesos. A partir dessa estruturação os poderes se permitem realizar funções atípicas ao mesmo tempo em que cada qual exerce suas funções típicas.

A teoria dos freios e contrapesos foi empregada pela primeira vez no começo de 1787 por John Adams, mas já era conhecida em 1651 (ALVES, 2013, p. 284). Sobre o assunto o mesmo autor ainda esclarece:

Dessa forma, o tema tem duas facetas: quando encarado sob a perspectiva da separação de poderes, apresenta sua dimensão negativa, de divisão, controle e limite do poder soberano; ao contrário, quando o problema é abordado sob a teoria do check and balances, enfatiza-se a dimensão positiva, de ordenação (ALVES, 2013, p. 284).

Continuamente, na explicação sobre a teoria dos pesos e contrapesos Machado expõe (2011, p. 98):

[...] no exercício de suas atribuições, cada função não está limitada ou estanque à sua competência exclusiva, exercendo, por vezes, as funções de outro Poder, qual seja, a competência concorrente. É que, como exemplo, à função judiciária compete, além da jurisdição, a administração de seu pessoal e seu orçamento.

\footnotetext{
${ }^{3}$ Art. $2^{\circ}$ São Poderes da União, independentes e harmônicos entre si, o Legislativo, o Executivo e o Judiciário.

${ }^{4}$ Art. 60. A Constituição poderá ser emendada mediante proposta: $§ 4^{\circ}$ Não será objeto de deliberação a proposta de emenda tendente a abolir: III - a separação dos Poderes;
} 
À função executiva compete, além de sua função governamental e administrativa, a função de julgar administrativamente. À função legislativa compete, além da função de julgar, em determinados casos. Verifica-se uma espécie de "entrelaçamento" de competências que, embora preserve a autonomia e a independência de cada função, ao mesmo tempo acaba por estabelecer uma interdependência entre as diferentes funções.

Diante do aclaramento apresentado é perceptível que em simultaneidade de tempo as funções se permitem e se restringem em uma intersecção de competências concorrentes e particulares. Como exemplo pode-se mencionar a atribuição de competência do processo legislativo ao Congresso Nacional (função legislativa) que, de acordo com o sistema em vigor, por intermédio do artigo 48 da Constituição Federal exige a sanção do Presidente da República que tem poder de veto (MACHADO, 2011, p. 100).

Em suas funções típicas, à função executiva cabe a chefia de Estado e de Governo e à função judicial compete o julgamento de conflitos e a proteção dos direitos fundamentais e da Constituição (MACHADO, 2011, p. 102/103). Porém, ainda que se perfaçam técnicas de controle do poder estatal como o sistema de freios e contrapesos, as crises institucionais não denotam a eficácia plena deste método.

Veja-se a situação dos direitos fundamentais. É fato que a desigualdade social no Brasil é alarmante, o que exige a intervenção do Estado em uma tentativa de distribuição da riqueza. No entanto, a função executiva, por vezes, não cumpre as políticas públicas necessárias para reversão e diminuição paulatina dos problemas relacionados aos direitos fundamentais, como o caso da saúde, da educação, da moradia, da previdência, entre outros.

Em alguns momentos o poder estatal alega a inviabilidade orçamentária e, então, as pessoas recorrem à função judicial, tendo em conta que sua competência constitucional é zelar pelos direitos fundamentais e pela Constituição. Neste limiar, quando um juiz determina ao executivo o cumprimento de políticas públicas, diz-se da ocorrência de uma quebra do sistema de freios e contrapesos, pois a função judicial não pode infringir as escolhas políticas da função executiva.

Nesse viés, Machado aponta que:

Decisões judiciais que concedem liminares para implementação de políticas públicas que não foram discutidas e aprova- 
das na seara competente ocasionam a preterição de outras, que por sua vez foram discutidas e aprovadas, e mais do que isso, realizam atribuição de direitos subjetivos a determinados indivíduos, em prejuízo de outros, na mesma situação de fato e de direito (2011, p. 122).

Para Alves (2013, p. 288) "apesar de a teoria da separação dos poderes ter relevância histórica, ela é uma teoria deficiente, mesmo quando considerada conjugada com as correções que lhes foram impostas pela teoria dos freios e contrapesos", isso instiga à tentativa de se utilizar novas práticas que possam aperfeiçoar as teorias já existentes.

\section{A conquista de território pelo Poder Judiciário: da doutrina da troca de sujeitos ao ativismo judicial}

A troca de sujeitos legitimados em casos de omissão inconstitucional ocorre quando o Poder Judiciário, ante a omissão do Poder Legislativo, investese de funções legislativas e produz a norma genérica e abstrata para regulação da situação fática para a qual não há regra legislada. A ideia principal que norteia a troca de sujeito é simples: mais importa cumprir a Constituição Federal, do que o sujeito que vai desempenhar esse papel.

A troca de sujeito em casos de omissão legislativa inconstitucional é doutrina relativamente nova no Brasil e não tem amparo constitucional frente ao disposto no art. $2^{\circ}$ da Constituição Federal, que tipifica o princípio da separação de Poderes. Nem mesmo uma Emenda Constitucional poderia inserir tal possibilidade na Constituição Federal de 1988, uma vez que a separação de Poderes é cláusula pétrea, nos termos do disposto no art. $60, \S 4^{\circ}$, inciso III da Constituição Federal.

Uma nova Constituição Federal, fruto do Poder Constituinte Originário Revolucionário, poderia sim inovar, trazendo essa possibilidade para o nosso ordenamento jurídico.

Atualmente, constatada uma omissão legislativa inconstitucional por meio da Ação Declaratória de Inconstitucionalidade supridora de omissão, declarada a inconstitucionalidade e dada ciência ao Poder Legislativo, fixa-se judicialmente a ocorrência de omissão, com efeitos retroativos ex tunc e erga omnes. A partir daí, caso da omissão decorra qualquer prejuízo, permite-se a responsabilização da entidade de direito público interno à qual esteja vincula- 
do o Poder Legislativo omisso.

Contudo, assumir o papel de Legislador positivo o Poder Judiciário não pode, sob pena de tentar sanar uma inconstitucionalidade, ou seja, a omissão com outra inconstitucionalidade, qual seja, a lei produzida pelo Judiciário.

A respeito desse tema, tem ganho corpo a discussão a respeito do chamado ativismo judicial.

O princípio da separação dos Poderes importa, dentre diversos outros consectários, na manutenção dos órgãos do Judiciário nos limites da função jurisdicional que lhes é confiada e para cujo exercício foram estruturados. A esse propósito, importa ter presente que, em contraposição à função legislativa, a atividade jurisdicional opera em escalão inferior da ordem jurídica e se volta, precipuamente, à atuação de atos normativos superiores, contribuindo, apenas, moderada e limitadamente, na modelagem do conteúdo desses atos (RAMOS, 2010, p. 117).

A discricionariedade judicial se distingue, nitidamente, das discricionariedades legislativa e administrativa, correspondendo à liberdade de escolha que se defere ao juiz diante de possibilidades exegéticas consistentes. Floresce ela no espaço que os balizamentos normativos autorizam o julgador a se movimentar, porém com a sensível diferença de que o controle, nesse caso, compete ao próprio órgão ao qual foi deferido o poder discricionário, o que não significa que possa, em harmonia com o sistema, tudo fazer.

Por ativismo judicial, o que os juristas alemães denominaram de "interpretação ilimitada da norma", deve-se entender o exercício da função jurisdicional para além dos limites impostos pelo próprio ordenamento que incumbe, institucionalmente, ao Poder Judiciário fazer atuar, resolvendo litígios de feições subjetivas (conflitos de interesse) e controvérsias jurídicas de natureza objetiva (conflitos normativos). Essa ultrapassagem das linhas demarcatórias da função jurisdicional se faz em detrimento, particularmente, da função legislativa, não envolvendo o exercício desabrido da legiferação (ou de outras funções não jurisdicionais) e sim a descaracterização da função típica do Poder Judiciário, com incursão insidiosa sobre o núcleo essencial de funções constitucionalmente atribuídas a outros Poderes (GOMES, 2009).

Se no positivismo clássico a interpretação se submete à vontade do legislador, dando ensejo ao fenômeno do passivismo judiciário, a consequência do pragmatismo e do moralismo jurídico é o ativismo subjetivista do intérprete-aplicador; amplo e explícito no primeiro caso, circunscrito e implícito, no segundo. 
Já no positivismo moderado ou renovado, o que prevalece é a vontade da lei, não no sentido de um pressuposto prévio, pronto e acabado, que o juiz tenha que meramente atender, mas no de que o texto normativo objeto de exegese contém algo de objetivo, que não pode ser desconsiderado, embora constitua apenas um limite no trabalho de construção da norma de decisão, em que também conta (embora não com o mesmo peso) a vontade do intérprete.

Se as decisões judiciais não são elaboradas livremente e se, tampouco, a discricionariedade do juiz é tão ampla quanto à do legislador, é nos limites substanciais que o próprio direito a aplicar lhe impõe (e não nos procedimentos formais que deve seguir para fazê-lo - due process of law) que se hão de buscar os critérios para a aferição da existência ou não de ativismo judiciário.

No campo da atuação do Estado é que se vê uma maior tendência ao ativismo judicial.

Enquanto se mantenha no plano exclusivamente político, a função de governo revela-se judicialmente incontrolável, o que se demonstra pelo fato de não envolver a prática de atos concretos, capazes de afetar a esfera jurídico-subjetiva de quem quer que seja, e, outrossim, porque mesmo o controle preventivo da constitucionalidade de atos do Poder Público jamais retroage a ponto de surpreender a planificação política da ação governamental.

Em algumas situações, o ordenamento brasileiro consagra um controle judicial de grau mínimo em relação a atividades estatais, como é o caso do exercício atípico de função jurisdicional pelo Senado, no processo e julgamento de crimes de responsabilidade, sindicável apenas sob o prisma da observância ao princípio do devido processo legal e seus consectários no plano formal.

Judicialização não se confunde com ativismo judicial. A judicialização nada mais expressa que o acesso judiciário, que é permitido a todos, contra qualquer tipo de lesão ou ameaça a um direito. É fenômeno que decorre do nosso modelo de Estado e de Direito.

Outra coisa bem distinta é o ativismo judicial, que retrataria uma espécie de intromissão indevida do Judiciário na função legislativa, ou seja, ocorre ativismo judicial quando o juiz "cria" uma norma nova, usurpando a tarefa do legislador; quando o juiz inventa uma norma não contemplada nem na lei, nem dos tratados, nem na Constituição.

Se a Constituição prevê um determinado direito e ela é interpretada no sentido de que esse direito seja garantido, para nós, isso não é ativismo judicial, sim, judicialização do direito considerado. $\mathrm{O}$ ativismo judicial vai muito 
além disso: ocorre quando o juiz inventa uma norma, quando cria um direito não contemplado de modo explícito em qualquer lugar, quando inova o ordenamento jurídico.

Há duas espécies de ativismo judicial:

- ativismo judicial inovador - criação, ex novo, pelo juiz de uma norma, de um direito e

- ativismo judicial revelador - criação pelo juiz de uma norma, de uma regra ou de um direito, a partir dos valores e princípios constitucionais ou a partir de uma regra lacunosa.

No último caso o juiz chega a inovar o ordenamento jurídico, mas não no sentido de criar uma norma nova, sim, no sentido de complementar o entendimento de um princípio ou de um valor constitucional ou de uma regra lacunosa.

O primeiro e principal dos parâmetros fornecidos pelo próprio ordenamento jurídico para a identificação do ativismo judicial diz respeito à exigência de que toda e qualquer interpretação constitucional seja compatível com a amplitude de sentidos projetada pelo texto da norma (limite da textualidade).

Tal limitação se configura por meio da plena utilização da metodologia exegética, compreendendo os seus múltiplos elementos, de cuja ponderação, à luz das circunstâncias do caso concreto (não necessariamente um conflito intersubjetivo), resulta a delimitação do espaço de interpretação disponível ao aplicador.

De outra parte, as exigências da percepção do direito como um sistema, axiologicamente orientado, importam na necessidade do intérprete-aplicador atentar para a existência de normas principiológicas implícitas e para a circunstância de que as normas, institutos e conceitos jurídicos que os expressam não estão simplesmente justapostos no ordenamento, havendo entre todas essas categorias vínculos funcionais que a correta operação do sistema jurídico pressupõe.

Registre-se, ainda, que a interpretação-aplicação da Constituição pelo Poder Judiciário, em sistemas constitucionais similares ao brasileiro, não pode ser feita mediante discricionária atribuição de efeitos às normas concretizadas, devendo o juiz se ater aos elementos hermenêuticos que, objetivamente, indiquem o seu enquadramento na categoria das normas de eficácia plena (restringível ou não) ou não das normas de eficácia limitada.

Nessa última hipótese, se afigura de crucial importância identificar se 
a integração do comando normativo é dependente apenas de providências jurídico-formais (normas preceptivas) ou se, bem além disso, exige a execução de um programa de ação estatal de cunho abrangente, que produza a indispensável adaptação da estrutura fático-material subjacente à normalização constitucional (normas programáticas). A norma do artigo $5^{\circ}, \S 1^{\circ}$, da Constituição encerra, a esse propósito, um princípio de interpretação, conexo ao da máxima efetividade, pelo qual as normas definidoras de direitos e garantias fundamentais devem ser concretizadas de modo a se lhes emprestar, sempre que possível, eficácia plena e aplicabilidade imediata, servindo o instituto do mandado de injunção de remédio à falta de regulamentação de norma preceptiva, veiculadora de direito ou garantia fundamental.

Segundo Ramos (2010, p. 218), interpretar a Constituição de uma maneira criativa é bem diferente de inventar normas. "O texto constitucional existe para ser interpretado. Se for feito de uma maneira evolutiva, dentro da norma, é bastante positivo. Mas, quando o juiz resolve transcender essa norma para sobrevalorizar princípios constitucionais, ele invade a sua competência e desprestigia o Poder Legislativo." O professor alerta que é preciso diferenciar o que é uma interpretação criativa de uma norma do que é pura criação de um juiz:

Quando digo que sou contra o ativismo, não estou dizendo que a decisão dos julgadores não foi justa, inadequada, menos ou mais equânime, mas quero deixar claro que não cabe ao Judiciário suprir essas lacunas. As decisões das instâncias inferiores ficam restritas ao estado, não causam impacto no país todo. Goste ou não, o Congresso é quem tem competência para legislar. O Judiciário não é o órgão adequado para fazer isso. Isso é destruição do Estado de Direito.

Se é certo que a legislação atual tende à ocasionalidade e à confusão, não menos certa é a constatação de que isso não nos permite deduzir que as sociedades modernas pretendam remeter aos magistrados os problemas últimos de seu livre - e por vezes defeituoso - ajuste social. Por muito que se ressalte a crise da lei nas sociedades atuais, tal crise não chega de modo algum a deslocar a lei do seu papel central e, até o momento, insubstituível.

As normas jurídicas não são simplesmente um conjunto de regras faladas, escritas ou formalizadas destinadas a constituir uma razão para o atuar dos indivíduos, que expressam ideologias dominantes ou que as pessoas se limitam a seguir. Em vez disso, as normas representam a formalização de regras 
de condutas sociais sobre as quais uma alta porcentagem de pessoas concorda, que refletem as inclinações comportamentais e oferecem benefícios potenciais e eficientes aqueles que as seguem: quando as pessoas não reconhecem ou não acreditam nesses benefícios potenciais, as normas são, com frequência, ignoradas ou desobedecidas.

A rapidez do progresso, da ciência, das transformações sociais, os temas ligados à engenharia genética - que fazem surgir cada vez mais problemas ético-jurídicos -, os avanços tecnológicos que não cessam de criar problemas novos e imprevisíveis, como as operações de clonagem humana, além da dependência em que se encontra a humanidade em relação à degradação do meio ambiente, e a evolução do direito ecológico, os avanços dos instrumentos de comunicação e informação, a insegurança política, com a propagação de guerras civis, tudo aliado ao fato de vivermos um cenário da globalização da economia.

O conjunto de direitos sociais, por sua vez, encontra-se abalado pela chamada política neoliberal, observando-se a necessidade de limitação de poder político e econômico, devendo o jurista e intérprete questionar a deficiência da hermenêutica jurídica tradicional, bem como a valorização dos direitos humanos e sociais.

Todas estas considerações são importantes para indagar o atual papel do magistrado, que ganhou maior amplitude, bem como os tradicionais métodos de interpretação em consequência das evoluções sociais que nem o legislador nem o Poder Judiciário puderam dominar e aos quais tiveram que se adaptar.

Não é mais é possível sustentar que o juiz é apenas "a boca da lei". A aplicação do direito não pode se resumir a um puro mecanismo, nem sequer a uma série de operações lógicas. É ilusória a facilidade de uma operação puramente lógica e mecânica.

Conclui-se que o Poder Judiciário não pode desconsiderar a repercussão social e política de suas decisões. Deve ocorrer uma maior aproximação entre as decisões prolatadas pelos magistrados e o Estado Social, através da superação de barreiras impostas pela hermenêutica tradicional.

Para que as leis sejam corretamente interpretadas, é de extrema importância que o Judiciário desfrute de real independência e esteja livre das pressões políticas engendradas por associação com o Executivo ou mesmo com o Legislativo.

A adoção de um excessivo rigor e formalismo técnico não é possível 
diante das constantes transformações sociais, o que se pode verificar na constante mudança na jurisprudência dos tribunais e nos posicionamentos doutrinários, ainda que não tenham sido objeto de alteração legislativa.

O Poder Judiciário não pode ficar limitado a ser mero aplicador da literalidade da lei, devendo ser mais do que nunca um sentinela de direitos fundamentais, um guardião em última análise da Constituição.

Portanto, é de grande importância a questão da interpretação das normas, principalmente na atualidade, no qual são postos em questão os paradigmas interpretativos tradicionais, que não são mais capazes de lidar com a ampla gama de conflitos surgidos nas sociedades complexas do final do século XX.

Ressalta Dalmo de Abreu Dallari (2007, p. 89-90):

O reconhecimento da politicidade do direito nada tem a ver com opções partidárias nem tira, por si só, a autenticidade e a legitimidade das decisões judiciais. Bem ao contrário disso, o juiz consciente dessa politicidade fará um esforço a mais para conhecer e interpretar o direito, considerando sua inserção necessária num contexto social, procurando distingui-lo do direito abstrato ou do que é criado artificialmente para garantir privilégios, proporcionar vantagens injustas ou impor sofrimentos a outros com base exclusivamente numa discriminação social.

Diante de tais considerações, defende-se que o ativismo judicial deve ser aspirado por todos os magistrados como forma de realizar o direito e a justiça social.

Assim vistas as coisas, aquilo que se chama, criticamente, de ativismo judicial não configura nenhum extravasamento de juízes e tribunais no exercício das suas atribuições, antes traduz a sua indispensável e assumida participação na tarefa de construir o direito de mãos dadas com o legislador, acelerando-lhe os passos, quando necessário, porque assim o exige um mundo que se tornou complexo demais para reger-se por fórmulas políticas acanhadas e ultrapassadas.

No entanto, vê-se que a função judicial não pode ser elevada ao patamar de "super herói" da sociedade, mas a teoria dos freios e contrapesos também não deve impedir oportunidades dialógicas entre as funções, uma vez que essa interação possibilita perspectivas de melhora na realidade de vida das pessoas, como é o caso da decretação do Estado de Coisas Inconstitucional (ECI). 


\section{$4 \mathrm{O}$ estado de coisas inconstitucional e o "compromisso significativo"}

O Estado de Coisas Inconstitucional tem origem nas decisões da Corte Constitucional Colombiana diante da constatação de violações generalizadas, contínuas e sistemáticas de direitos fundamentais. Tem por finalidade a construção de soluções estruturais voltadas à superação desse lamentável quadro de violação massiva de direitos das populações vulneráveis em face das omissões do poder público.

Segundo a Corte Constitucional Colombiana, o ECI caracteriza-se, fundamentalmente, diante da constatação de que: (a) é grave, permanente e generalizada a violação de direitos fundamentais, que afeta a um número amplo e indeterminado de pessoas (na hipótese, não basta a ocorrência de uma proteção insuficiente), (b) há comprovada omissão reiterada de diversos e diferentes órgãos estatais no cumprimento de suas obrigações de proteção dos direitos fundamentais, que deixam de adotar as medidas legislativas, administrativas e orçamentárias necessárias para evitar e superar essa violação, consubstanciando uma falta estrutural das instâncias políticas e administrativas (isto é, não basta, para caracterizar o ECI, a omissão de apenas um órgão ou uma autoridade), (c) existe um número elevado e indeterminado de pessoas afetadas pela violação; e (d) há a necessidade de a solução ser construída pela atuação conjunta e coordenada de todos os órgãos envolvidos e responsáveis, de modo que a decisão do Tribunal é dirigida não apenas a um órgão ou autoridade, mas sim a uma pluralidade órgãos e autoridades, visando à adoção de mudanças estruturais (como, por exemplo, a elaboração de novas políticas públicas, a alocação de recursos, etc.) (CAMPOS, 2015).

Trata-se de construção jurisprudencial da Corte Constitucional colombiana, que tratou do assunto pela primeira vez na Sentencia de Unificación (SU) $n^{0} 559$, de 1997. Nesse caso, a Corte Constitucional constatou existir um descumprimento generalizado dos direitos previdenciários de um grupo de 45 (quarenta e cinco) professores de dois municípios colombianos e de um grupo ainda maior que era alcançado pela situação. Declarou o "estado de coisas inconstitucional" e determinou que os municípios envolvidos encontrassem solução para a inconstitucionalidade em prazo razoável.

Depois de algumas experiências malsucedidas, a Corte colombiana passou a aperfeiçoar o instituto em decisões posteriores. 
Na Sentencia de Tutela (T) $\mathrm{n}^{\circ} 25$, de 2004, a Corte apreciou 108 (cento e oito) pedidos de tutelas formulados por 1.150 (mil e cinquenta) núcleos familiares deslocados. Declarou o "estado de coisas inconstitucional"; exigiu atenção orçamentária especial ao problema; determinou que fossem formuladas novas políticas públicas, leis e um marco regulatório eficiente para proteger os direitos individuais dos demandantes. Diferentemente do ocorrido com o caso do sistema carcerário, desta vez as ordens foram flexíveis, dirigidas a um número elevado de autoridades públicas, além de ter havido intenso diálogo da Corte com os outros Poderes e com a sociedade sobre a adequação das medidas judiciais determinadas durante a fase de sua implementação (CAMPOS, 2015).

No Brasil, o debate sobre a figura do "estado de coisas inconstitucional" a legitimar uma ação mais incisiva do Poder Judiciário no que concerne à implementação de políticas públicas e à alocação de recursos orçamentários ganhou relevo, recentemente, com o julgamento, no STF, do RE $n^{\circ} 592.581$ e da ADPF $n^{\circ} 347$.

Em 13 de agosto de 2015, o Plenário do STF decidiu que o Poder Judiciário pode determinar que a administração pública realize obras ou reformas emergenciais em presídios para garantir os direitos fundamentais dos presos, como sua integridade física e moral. A decisão foi tomada no julgamento do RE $n^{\circ}$ 592.581, com repercussão geral, interposto pelo Ministério Público do Rio Grande do Sul (MP/RS), relator o Ministro Ricardo Lewandowski, contra acórdão do Tribunal de Justiça local (TJ/RS). O TJ entendera não caber ao Poder Judiciário intervir em matéria reservada à competência administrativa do Poder Executivo gaúcho.

O tema da repercussão geral era o de $\mathrm{n}^{\circ} 220$ e estabelecia:

Competência do Poder Judiciário para determinar ao Poder Executivo a realização de obras em estabelecimentos prisionais com o objetivo de assegurar a observância de direitos fundamentais dos presos.

Eis o que decidido pelo STF:

O Tribunal, por unanimidade e nos termos do voto do Relator, apreciando o tema 220 da repercussão geral, deu provimento ao recurso extraordinário para cassar o acórdão recorrido, a fim de que se mantenha a decisão proferida pelo juízo de primeiro grau. Ainda por unanimidade, o Tribunal assentou a seguinte tese: É 
lícito ao Judiciário impor à Administração Pública obrigação de fazer, consistente na promoção de medidas ou na execução de obras emergenciais em estabelecimentos prisionais para dar efetividade ao postulado da dignidade da pessoa humana e assegurar aos detentos o respeito à sua integridade física e moral, nos termos do que preceitua o art. $5^{\circ}$, XLIX, da Constituição Federal, não sendo oponível à decisão o argumento da reserva do possível nem o princípio da separação dos poderes.

Nesta decisão, fica evidenciada a heterodoxa posição do STF ao balancear os direitos e princípios constitucionais tutelados, no sentido de impor obrigação de fazer ao Poder Executivo no âmbito da política penitenciária, para dar efetividade ao princípio constitucional da dignidade da pessoa humana e assegurar aos detentos o respeito à sua integridade física e moral, afastados os princípios da separação dos Poderes e da reserva do financeiramente possível. (CAMPOS, 2015).

Ao que tudo indica, mais um passo está sendo dado pelo Poder Judiciário no que se refere ao grau de interferência de suas ações na formulação de políticas públicas para a proteção de direitos fundamentais. O caminho, agora, aprece apontar para a figura do "compromisso significativo" (meaningful engagement), cuja técnica vem sendo desenvolvida pela Corte Constitucional da África do Sul, a possibilidade de adoção de providências alternativas com vistas a reequilibrar os princípios e regras constitucionais envolvidos quando detectado um "estado de coisas inconstitucional", vale dizer, quando direitos fundamentais não são efetivados pelo Poder Executivo (VIEIRA CAMPOS, 2015).

Para David Pardo, a grande vantagem do compromisso significativo sobre as decisões judiciais que interferem diretamente na priorização de políticas públicas e na alocação de recursos orçamentários por parte do Poder Executivo é a construção de uma solução pactuada, participativa, sob a fiscalização do Poder Judiciário. Segundo ele:

O método do compromisso significativo apresenta a vantagem de ser modelo de revisão judicial compatível com a democracia. Propicia que os indivíduos e comunidades sejam posicionados como parceiros no processo de tomada de decisões, que a decisão final seja construída em conjunto. Constitui postura judicial respeitosa com os representantes eleitos pelo público e fomenta a participação e a política democrática. De outro lado, a organização financeira do Estado é mais bem respeitada, pois há 
oportunidade para as próprias partes detalharem a forma de implementação de direitos, modulando-a de acordo com os recursos disponíveis. O controle imediato do orçamento permanece com a administração pública, ainda que sob a ordem judicial de atendimento aos direitos. A ideia é que o Estado deve se comprometer significativamente com a situação em que há violação dos direitos, por meio de iniciativas e políticas para uma solução razoável e tempestiva, antes de receber veredito judicial substantivo. A alternativa à intervenção judicial em políticas públicas é o jogo interativo mais rico e complexo, não a imunidade total da Administração Pública, nem a prevalência absoluta dos juízes. O compromisso significativo bem podia ser testado como novo padrão positivo de relacionamento entre os tribunais e os demais poderes no Brasil.

O "compromisso significativo" é um processo determinado pelo Poder Judiciário, de constante intercâmbio entre cidadãos e comunidades, de um lado, e o Estado, de outro, em que as partes tentam, a partir da compreensão das perspectivas do outro, um acordo na formulação e implementação de programas socioeconômicos que afetam comunidades ou grupos de pessoas (CHENWI \& TISSINGTON, 2010, p. 10-11).

O processo do "compromisso significativo" deve, necessariamente, ser bem estruturado, coordenado, consistente e compreensivo e deve habilitar cidadãos ou comunidades a serem tratados como parceiros no processo de tomada de decisão (CHENWI \& TISSINGTON, 2010, p. 9).

A questão que pode surgir é se a Constituição de 1988 daria abrigo à aplicação do "compromisso significativo" em terras brasileiras. A doutrina atesta que a resposta é positiva (VIEIRA JUNIOR, 2015):

Interessante constatar que a Constituição brasileira, em seu preâmbulo (papel do Estado destinado a assegurar o exercício dos direitos sociais e individuais); em seus fundamentos (cidadania, dignidade da pessoa humana e exercício do poder, direta ou indiretamente, pelo povo - art. $1^{\circ}$, II e III, e parágrafo único da $\mathrm{CF}$ ); em seus objetivos fundamentais (construir uma sociedade livre, justa e solidária, garantir o desenvolvimento nacional, erradicar a pobreza e a marginalização e reduzir as desigualdades sociais e regionais, promover o bem de todos sem preconceitos de qualquer espécie - art. $3^{\circ}$, I, II, III e IV); em seus direitos e garantias fundamentais e na parte referente à administração pública (direito a receber informações dos órgãos públicos, direito 
de petição aos Poderes Públicos, direito de obter certidões em repartições públicas, participação dos usuários na administração pública e direitos dos usuários na prestação de serviços públicos - art. $5^{\circ}$, XXXIII e XXXIV, art. 37, § $3^{\circ}$, art. 175, parágrafo único, II, da CF); e em seus direitos sociais (art. $6^{\circ}$, caput), fornece o lastro para amparar uma solução dialógica, talvez não idêntica, mas inspirada no modelo sul-africano.

Parece-nos, pelas razões expostas e por suas próprias características, que o "compromisso significativo" é figura mais apropriada do que o reconhecimento de "estado de coisas inconstitucional" no que tange à determinação, pelo Poder Judiciário, de medidas a serem implementadas pelo Poder Executivo de forma a assegurar direitos fundamentais, com vistas à preservação da isonomia e harmonia dos Poderes, cláusula imodificável de nossa Constituição, por força do que determina o art. 60 , § $4^{\circ}$, inciso III.

Convém destacar, todavia, que o "compromisso significativo" é construção da Corte Constitucional sul-africana, não sendo disciplinada formalmente por norma legal.

Atento a isso, o Senador Antônio Carlos Valadares apresentou, em 11 de novembro de 2015, o Projeto de lei do Senado (PLS) n ${ }^{\circ} 736$, de 2015, que:

altera as Leis $\mathrm{n}^{\circ}$ 9.882, de 3 de dezembro de 1999, e 13.105, de 16 de março de 2015, para estabelecer termos e limites ao exercício do controle concentrado e difuso de constitucionalidade pelo Supremo Tribunal Federal, dispor sobre o reconhecimento do estado de coisas inconstitucional e o compromisso significativo.

Trata-se de iniciativa parlamentar inédita na tentativa de disciplinar o reconhecimento do "estado de coisas inconstitucional" e o "compromisso significativo", no âmbito do sistema de controle da constitucionalidade das normas no Brasil.

O objetivo central da proposição fica evidenciado a partir de sua leitura, qual seja, a construção compartilhada de uma solução pela administração pública e pelos interessados - precisamente identificados na ADPF ou no RE -, a partir de diretrizes fixadas pelo Poder Judiciário.

Pela proposição, o compromisso significativo possui o claro intuito de tornar efetivo o preceito fundamental sonegado, ponderados os princípios e normas constitucionais envolvidos. 


\section{Conclusão}

Ao longo de sua trajetória o Poder Judiciário de "boca da Lei" tornouse um poder protagonista. A proclamada inércia da Jurisdição deu lugar ao ativismo escancarado, na busca de conferir eficácia, em especial, aos direitos fundamentais sociais.

Ante a reconhecida inércia dos Poderes Legislativo e Executivo, o vácuo por eles deixado foi ocupado pelo Poder Judiciário, na tentativa de obrigar os poderes omissos a atuarem de forma a propiciar o efetivo gozo sem que óbices como limitações orçamentárias e outras deficiências estruturais pudessem justificar a ausência de atuação.

Ao invés de limitar-se ao papel de expectador do não fazer, o Judiciário começou a atuar de forma mais ativa, determinado a verdadeira implementação de políticas públicas capazes de atender ao anseio da população na exata medida do que foi prometido pela Constituição de 1988.

Por meio do rotulado ativismo judicial, os juízes deixaram de lado o papel de legislador negativo e passaram a atuar como verdadeiros legisladores, ativos, implementando normas capazes de fazer valer os ditames da Constituição Federal.

Desvios ocorreram, é verdade, e o propalado ativismo deixou de ser a tábua de salvação dos oprimidos, já que o conteúdo de determinações verticais impostas a uma canetada em muitos casos tornou-se impossível de cumprimento, haja vista as limitações materiais para o atendimento de ordens emanadas de um Judiciário que apenas mandava, se se preocupar como seria operacionalizado, na prática, o conteúdo mandamental do decidido.

Nesse momento, surge a doutrina do "estado de coisas inconstitucional", que busca superar bloqueios políticos e institucionais, e aumentar a deliberação e o diálogo sobre causas e soluções do Estado de Coisas Inconstitucional. É o já conhecido ativismo judicial, mas agora em seara estrutural e não tão somente material.

Aprendendo com os próprios erros, as cortes judiciais brasileiras estão descobrindo que não podem resolver o quadro atuando isoladamente, e que de nada adiantará proferirem decisões impossíveis de serem cumpridas. Cortes devem adotar ordens flexíveis e monitorar a sua execução, ao invés de adotar ordens rígidas e se afastar da fase de implementação das medidas. Fica de lado a vetusta ideia de supremacia judicial; as cortes devem abrir e manter o diálogo 
com as demais instituições em torno das melhores soluções. O ativismo judicial é estrutural, mas pode e deve ser dialógico.

A opção de partir para o diálogo institucional promove vantagens democráticas e ganho de efetividade prática de suas decisões, contribuindo realmente para melhoria da situação.

O mais atual estágio do caminho escolhido pelo judiciário ativo é o chamado "compromisso significativo", expediente que Corte Constitucional sul-africana desenvolveu, ao longo de uma década, importante técnica para a proteção de direitos que exigiam a ação administrativa do Estado. A grande vantagem do compromisso significativo sobre as decisões judiciais que interferem diretamente na priorização de políticas públicas e na alocação de recursos orçamentários por parte do Poder Executivo é a construção de uma solução pactuada, participativa, sob a fiscalização do Poder Judiciário.

$\mathrm{O}$ "compromisso significativo", produção original da Corte Constitucional sul-africana, está em vias de se tornar norma no Brasil, com Projeto de lei do Senado (PLS) $n^{\circ} 736$, de 2015, que altera as Leis $n^{\circ}$ 9.882, de 3 de dezembro de 1999, e 13.105, de 16 de março de 2015, para estabelecer termos e limites ao exercício do controle concentrado e difuso de constitucionalidade pelo Supremo Tribunal Federal, dispor sobre o reconhecimento do estado de coisas inconstitucional e o compromisso significativo. O Projeto de Lei é de autoria do Senador Antonio Carlos Valadares.

O florescer desse Projeto de Lei parece anunciar bons frutos capazes de efetivamente harmonizar os Poderes no Brasil, mantendo-se conhecida divisão material entre eles.

\section{Referências}

ALVES, Fernando de Brito. Constituição e participação popular: a construção histórico-discursiva do conteúdo jurídico-político da democracia como direito fundamental. Curitiba: Juruá, 2013.

ALVES, Vital Francisco C. A relação entre o poder legislativo e o poder executivo no contrato social de Jean-Jacques Rousseau. Synesis, n 2, 2009. 
BRASIL. Constituição Federal da República Federativa do Brasil. Disponível em: <http://www.planalto.gov.br/ccivil_03/Constituicao/Constituicao.htm>. Acesso em: 08 maio 2016.

BRASIL. Senado Federal. Projeto de Lei do Senado (PLS) $\mathbf{n}^{0}$ 736, de 2015, do Senador Antônio Carlos Valadares. Disponível em http://www25.senado.leg.br/ web/atividade/materias/-/materia/124010. Acesso em 10.05.2016.

BRASIL. SUPREMO TRIBUNAL FEDERAL. Ementas dos acórdãos citados no texto. Disponíveis em http://www.stf.jus.br/portal/jurisprudencia/pesquisar Jurisprudencia.asp

CAMPOS, Carlos Alexandre de Azevedo. O Estado de Coisas Inconstitucional e o litígio estrutural. Disponível em http://www.conjur.com.br/2015-set-01/carloscamposestado-coisas-inconstitucional-litigio-estrutural. Acesso em 15/05/2016.

CHENWI, Lilian \& TISSINGTON, Kate. Engaging meaninfully with government on socio-economic rights: a focus on the right to housing. University of the Western Cape: Community Law Centre, March, 2010.

DALLARI, Dalmo de Abreu. O poder dos juízes. 3. ed. São Paulo: Saraiva, 2007.

DOURADO, E. A. N.; AUGUSTO, N. F.; ROSA, C. M. A. C. Dos três poderes de Montesquieu à atualidade e a interferência do Poder Executivo no Legislativo no âmbito brasileiro. In: V Congresso Internacional de História. 2011. Disponível em <http:/ / www.cih.uem.br/anais/2011/trabalhos/213.pdf>. Acesso em 08 maio 2016.

GOMES, Luiz Flávio. O STF está assumindo um "ativismo judicial" sem precedentes? 2009. Disponível em http://www.migalhas.com.br/depeso/16,mi87133,91041-o+stf+esta+assumindo+um+ativismo+judicial+sem+precedentes. Acesso em $18 / 05 / 2016$.

HÄBERLE, Peter. Hermenêutica Constitucional: A Sociedade Aberta dos Intérpretes da Constituição: Contribuição para a Interpretação Pluralista e "Procedimental" da Constituição. Trad. Gilmar Ferreira Mendes. Porto Alegre: Sergio Fabris Editor, 1997.

MACHADO, Edinilson Donisete. Ativismo judicial: limites institucionais democráticos e constitucionais. São Paulo: Letras Jurídicas, 2011. 
MONTESQUIEU, Charles de Secondat, Baron de. O espírito das leis. Apresentação: Renato Janine Ribeiro. Tradução: Cristina Murachco. São Paulo: Martins Fontes, 1996.

PARDO, David. Judiciário e políticas públicas ambientais: uma proposta de atuação baseada no "compromisso significativo. In: Revista de Direito Ambiental, $\mathbf{n}^{0}$ 72, out/dez 2013.

PEIXINHO, Manoel Messias. O princípio da separação dos poderes, a judicialização da política e direitos fundamentais. Revista de Direitos e Garantias Fundamentais. Vitória, n. 4, p. 13-44, jul./dez. 2008.

RAMOS, Elival da Silva. Ativismo judicial. São Paulo: Saraiva, 2010.

VIEIRA JUNIOR, R. J. A. Separação de Poderes, Estado de Coisas Inconstitucional e Compromisso Significativo: novas balizas à atuação do Supremo Tribunal Federal. Brasília: Núcleo de Estudos e Pesquisas/CONLEG/Senado, Dezembro/2015 (Texto para Discussão n ${ }^{\circ}$ 186). Disponível em: www.senado. leg.br/estudos. Acesso em 17/05/2016. 